\title{
Metal-Hydrogen-Pi-Bonded Organic Frameworks
}

Jie Zhu ${ }^{1 \neq}$, Laura Samperisi ${ }^{2 \ddagger}$, Mark Kalaj ${ }^{1}$, Jerika A. Chiong ${ }^{1}$, Jake B. Bailey ${ }^{1}$, Zhiyin Zhang ${ }^{1}$, Chung-Jui Yu ${ }^{1}$, R. Eric Sikma ${ }^{1}$, Xiaodong Zou ${ }^{2}$, Seth M. Cohen ${ }^{1}$, Zhehao Huang ${ }^{2 *}$, F. Akif $\operatorname{Tezcan}^{1 *}$

${ }^{1}$ Department of Chemistry and Biochemistry, University of California, San Diego, 9500 Gilman Drive, La Jolla, CA 92093

${ }^{2}$ Department of Materials and Environmental Chemistry, Stockholm University, Stockholm SE106 91, Sweden

KEYWORDS. MOFs, Hydroxamate-based

ABSTRACT: We report the synthesis and characterization of a new series of permanently porous, three-dimensional metal-organic frameworks (MOFs), M-HAF-2 (M= Fe, Ga or In), constructed from tetratopic, hydroxamate-based, chelating linkers. The structure of M-HAF-2 was determined by three-dimensional electron diffraction (3DED), revealing a unique interpenetrated hcb-a net topology. This unusual topology is enabled by the presence of free hydroxamate groups, which lead to the formation of a diverse network of cooperative interactions comprising single metalhydroxamate nodes, staggered $\pi-\pi$ interactions between linkers and H-bonding interactions 
between metal-coordinated and free hydroxamate groups. Such extensive, multimodal interconnectivity is reminiscent of the complex noncovalent interaction networks of proteins and endows M-HAF-2 frameworks with good thermal and exceptionally high chemical stability and allows them to readily undergo post-synthetic metal exchange (PSE). We demonstrate that MHAF-2 can serve as versatile porous materials for ionic separations, likely aided by onedimensional channels lined by continuously $\pi$-stacked aromatic groups and H-bonding hydroxamate functionalities. As a new addition to the small group of hydroxamate-based MOFs, M-HAF-2 represents a structural merger between MOFs and hydrogen-bonded organic frameworks (HOFs).

\section{INTRODUCTION}

Metal-organic frameworks (MOFs) are crystalline porous materials constructed from inorganic nodes and organic linkers. ${ }^{1-2}$ Based on the Cambridge Crystallographic Data Centre (CCDC), more than 70,000 MOF structures ${ }^{3}$ have been reported with applications proposed in gas storage and separation, ${ }^{4-7}$ biomedical imaging and drug delivery, ${ }^{8-9}$ molecular sensing, ${ }^{10-11}$ and catalysis. ${ }^{12-14}$ To date, most MOFs have relied on the combination of carboxylate- or azole-based linkers and polynuclear metal clusters as secondary building units (SBUs), including some of the most versatile MOFs, such as MOF-5 ${ }^{15}$, ZIFs (zeolitic imidazolate frameworks) ${ }^{16-17}$, and the MIL (Material Institute Lavoisier), ${ }^{18-19} \mathrm{UiO}$ (University of Oslo), ${ }^{20} \mathrm{NU}$ (Northwestern University) ${ }^{21}$ and PCN (porous coordination network) ${ }^{22}$ series. Expanding upon the existing repertoire of MOF topologies may engender new emergent properties within these reticular materials. ${ }^{23-24}$ Exciting possibilities to create new materials with different functions including selective gas adsorption for chemical separations ${ }^{25-26}$ or introducing catalytic sites to improve the desired catalytic activities. ${ }^{27}$ 
Despite the central role of chelating groups in synthetic inorganic chemistry, linkers with multidentate functionalities are sparingly employed for MOF construction. This is likely due the fact that chelating linkers tend to yield SBUs with low connectivities, in addition to the possibility that their relatively slower metal exchange kinetics (compared to carboxylates or azoles) may hinder the formation of crystalline frameworks. Yet, given the remarkable structural and functional/electronic diversity of metal-chelate coordination complexes $^{28-29}$, the use of chelating motifs in MOF construction represents a potentially powerful strategy for the discovery of MOFs with new structures/topologies and chemical/physical properties. ${ }^{30-37}$

Accordingly, we have begun to explore organic linkers bearing hydroxamate chelating motifs in MOF construction. Hydroxamates are hard, Lewis basic, bidentate ligands and enable exceptionally stable coordination of transition metal ions such as $\mathrm{Fe}^{3+}, \mathrm{Ga}^{3+}$ and $\mathrm{Al}^{3+}, 38$ as demonstrated by bacterial siderophores in nature. ${ }^{39-41}$ Unlike carboxylate groups, hydroxamates allow asymmetric binding modes with metal ions and favor the formation of single metal nodes over polynuclear SBUs. To date, only four MOFs ${ }^{42-45}$ containing hydroxamate ligands have been reported, with only two ${ }^{42-43}$ having 3D framework structures.

Previously, we reported the first Fe-hydroxamate-based MOF (Fe-HAF-1), using biphenyl tetrahydroxamic acid $\left(\mathrm{H}_{4} \mathrm{BPTH}\right)$ as the linker and a single $\mathrm{Fe}^{3+}$ center as the node (Figure 1). ${ }^{43}$ The 1, 3 positioning of the hydroxamic groups on the phenyl rings coupled with the octahedral Fe-trishydroxamate coordination gave rise to the formation of tetrahedral, four-iron-six-linker clusters (as first reported by Raymond and colleagues ${ }^{46}$ ) as SBUs which were interconnected to yield the desired cubic, 3D framework structure. Despite featuring single-metal nodes, Fe-HAF-1 was found to display exceptional chemical stability maintaining crystallinity in aqueous solutions at $\mathrm{pH}$ 1-14 as well as in the presence of coordinating solvents. 

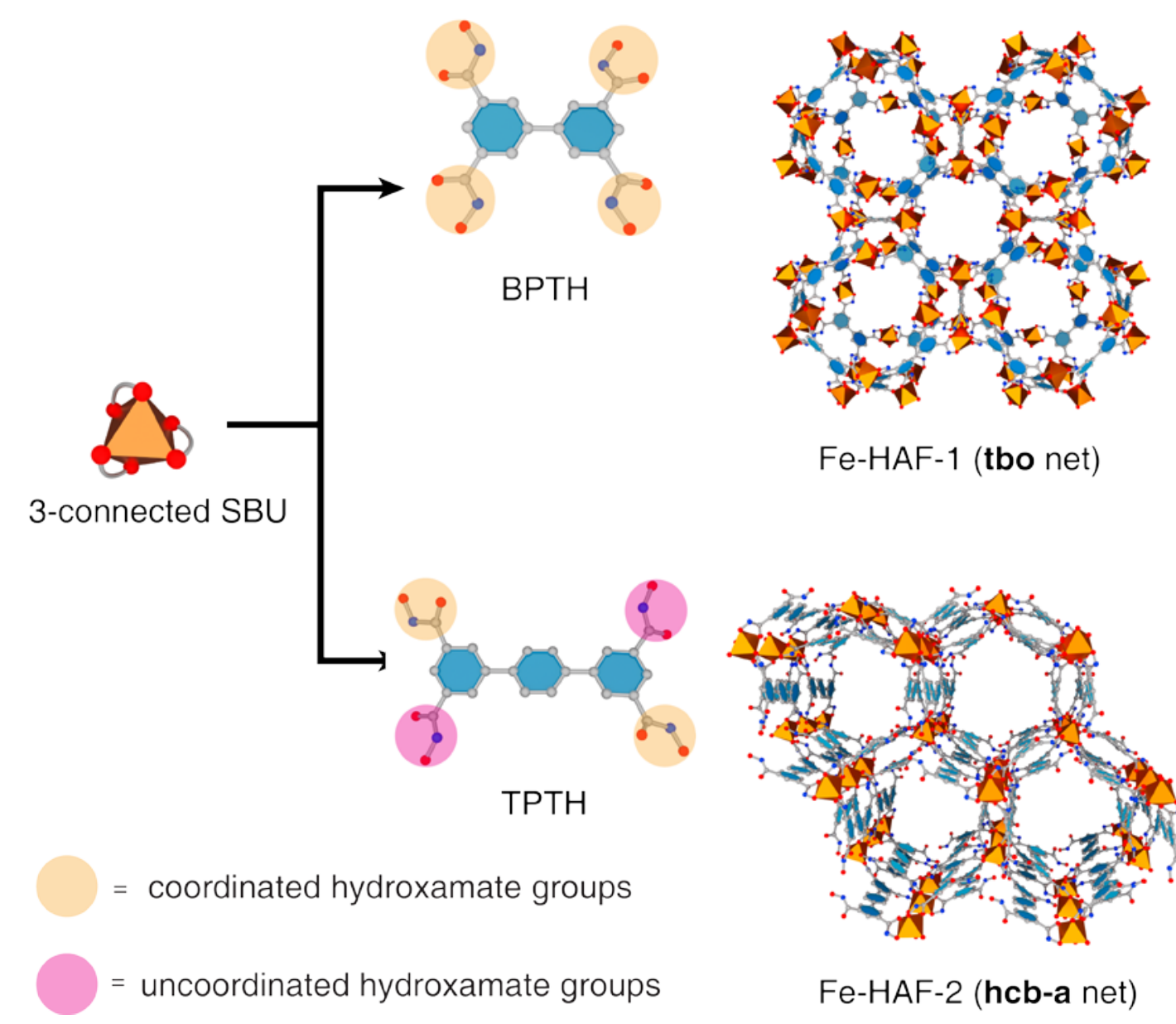

$$
\text { Fe-HAF-1 (tbo net) }
$$

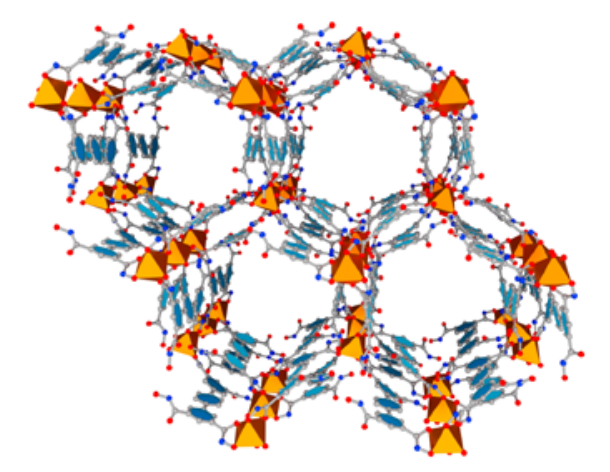

Fe-HAF-2 (hcb-a net)

Figure 1. Assembly of BPTH or TPTH with 3-connected SBUs lead to tbo net (Fe-HAF-1) or hcb-a net (Fe-HAF-2).

In the current study, we set out to investigate whether we could use linker design to extend the pore and aperture size of Fe-HAF-1 and expand the library of hydroxamate-based MOFs. Toward this end, we synthesized a longer linker (terphenyl tetrahydroxamic acid, H4TPTH). However, instead of the expected isoreticular expansion of Fe-HAF-1, we obtained a new series of MOFs, denoted as M-HAF-2 (M = Fe, In, Ga), which possesses an unusual interpenetrated hcb-a net topology, wherein the tetratopic linkers $\left(\mathrm{H}_{4} \mathrm{TPTH}\right)$ are two-connected and act as ditopic linkers with two remaining uncoordinated hydroxamate groups (Figure 1). Interestingly, the uncoordinated hydroxamate groups form intermolecular hydrogen bonds (H-bonds) with metal- 
coordinated hydroxamate groups within the framework that are further buttressed by extensive $\pi-$ $\pi$ interactions. Compared to Fe-HAF-1, which is only supported by coordination bonds, the synergy between three different types of interactions (metal coordination, $\pi-\pi$, and H-bonding) results in a porous framework material that is not only chemically but also physically stable, retains its crystallinity after activation, can be prepared de novo using different hard metal ions or readily undergo post-synthetic metal exchange (PSE). With its unusually intricate network of noncovalent interactions, Fe-HAF-1 represents an amalgamation of MOFs and H-bonded organic frameworks (HOFs), approximating the bonding complexity of proteins. In general, our study illustrates the benefits of expanding the toolkit of metal coordinating functionalities for the discovery of new structure/bonding modalities in MOF design.

\section{EXPERIMENTAL SECTION}

Materials and Methods.

All chemicals were purchased from commercial sources and used without further purification unless otherwise mentioned.

Synthesis of Fe-HAF-2. $\mathrm{FeCl}_{3} \cdot 6 \mathrm{H}_{2} \mathrm{O}(8.1 \mathrm{mg}, 0.03 \mathrm{mmol})$ and $\mathrm{H}_{4} \mathrm{TPTH}(13.98 \mathrm{mg}, 0.03 \mathrm{mmol})$ were added in a mixed solution of containing $1.8 \mathrm{~mL} N, N$-diethylformamide (DEF) and $0.2 \mathrm{~mL}$ acetonitrile (ACN) (v:v = 9:1) in a 1-dram vial and sonicated for $10 \mathrm{~min}$. Then, the solution was heated in a $60{ }^{\circ} \mathrm{C}$ oven for $48 \mathrm{~h}$. After cooling to $25{ }^{\circ} \mathrm{C}$, the resultant solid was isolated by centrifugation, washed with fresh DEF $(3 \times 1 \mathrm{~mL})$, and acetone $(3 \times 1 \mathrm{~mL})$. Orange crystalline powders were obtained ( $7 \mathrm{mg}, 32 \%$ yield). 
Synthesis of In-HAF-2. $\mathrm{InBr}_{3}(21.2 \mathrm{mg}, 0.06 \mathrm{mmol})$ and $\mathrm{H}_{4} \mathrm{TPTH}(13.98 \mathrm{mg}, 0.03 \mathrm{mmol})$ were added in a mixed solution of $1 \mathrm{~mL}$ DEF and $1 \mathrm{~mL}$ acetonitrile $(\mathrm{v}: \mathrm{v}=1: 1)$ in a 1-dram vial and sonicated for $10 \mathrm{~min}$. Then, the solution was heated in a $100{ }^{\circ} \mathrm{C}$ oven for $48 \mathrm{~h}$. After cooling to 25 ${ }^{\circ} \mathrm{C}$, the resultant solid was isolated by centrifugation, washed with fresh $\mathrm{DEF}(3 \times 1 \mathrm{~mL})$, and acetone $(3 \times 1 \mathrm{~mL})$. White crystalline powders were obtained (7 mg, 30\% yield).

Synthesis of Ga-HAF-2. The stock solution of $\mathrm{GaCl}_{3}$ in DEF $(100 \mathrm{mg} / \mathrm{mL})$ was prepared because $\mathrm{GaCl}_{3}$ is hygroscopic in air. $53 \mu \mathrm{L}$ of $\mathrm{GaCl}_{3}(5.28 \mathrm{mg}, 0.03 \mathrm{mmol})$ stock solution and $\mathrm{H}_{4} \mathrm{TPTH}$ (9.33 mg, $0.02 \mathrm{mmol}$ ) were added in a mixed solution of containing $1.4 \mathrm{~mL}$ DEF and 0.6 $\mathrm{mL}$ acetonitrile (v:v = 7:3) in a 1-dram vial and sonicated for $10 \mathrm{~min}$. Then, the solution was heated in a $100{ }^{\circ} \mathrm{C}$ oven for $48 \mathrm{~h}$. After cooling to $25^{\circ} \mathrm{C}$, the resultant solid was isolated by centrifugation, washed with fresh DEF $(3 \times 1 \mathrm{~mL})$, and acetone $(3 \times 1 \mathrm{~mL})$. Ivory crystalline powders were obtained (6 mg, 40\% yield).

Single Crystal Electron Diffraction Analysis. Continuous rotation electron diffraction (cRED) data were collected under cryogenic conditions (98 K) on a $200 \mathrm{kV} \mathrm{JEOL} \mathrm{JEM-2100-LaB} 6$ transmission electron microscope (Cs $1.0 \mathrm{~mm}$, point resolution $0.23 \mathrm{~nm}$ ) equipped with a Timepix detector from Amsterdam Scientific Instruments. Images were recorded with a Gatan Orius 833 CCD camera (resolution 2048×2048 pixels, pixel size $7.4 \mu \mathrm{m}$ ) under low dose conditions.

X-Ray Diffraction Analyses. Powder X-ray diffraction (PXRD) patterns were measured at room temperature in transmission mode on a Bruker SMART Pt135 CCD diffractometer equipped with $\mathrm{Cu} \mathrm{K} \alpha$ radiation $(\lambda=1.54178 \AA)$ calibrated with $\mathrm{AgBeH}$. Images were stitched together and azimuthally averaged using DIFFRAC.EVA. The dry powder samples were mounted on cryoloops with Paratone oil. 
Sample Activation and $\mathbf{N}_{2}$ Gas Sorption Analysis. Before a gas sorption experiment, assynthesized M-HAF-2 ( 50 mg) samples were washed with DEF three times and acetone three times, followed by soaking in acetone for 3-5 days to allow solvent exchange. During the solvent exchange process, the acetone was replaced with fresh solvent at least 3 times every 24 h. The resulting exchanged samples were evacuated in a vacuum oven overnight at $100{ }^{\circ} \mathrm{C}$ prior to analysis. Then the samples were degassed at $120^{\circ} \mathrm{C}$ on a Micromeritics ASAP 2020 Adsorption Analyzer for a minimum of $12 \mathrm{~h}$ prior to gas adsorption/desorption measurements. Sorption data and BET surface area $\left(\mathrm{m}^{2} / \mathrm{g}\right)$ measurements were collected at $77 \mathrm{~K}$ with $\mathrm{N}_{2}$ on a Micromeritics ASAP 2020 Adsorption Analyzer using volumetric technique.

Thermogravimetric Analysis (TGA). $5 \mathrm{mg}$ of sample was placed in a $100 \mu \mathrm{L}$ aluminum crucible. Samples were analyzed on a Mettler Toledo Star TGA/DSC using a temperature range of $30-500{ }^{\circ} \mathrm{C}$ scanning at $5^{\circ} \mathrm{C} / \mathrm{min}$ synthetic air $\left(75 \mathrm{~cm}^{3} / \mathrm{min}\right.$ air flow rate) for sample degradation measurements and a heat-cool-heat procedure at $10^{\circ} \mathrm{C} / \mathrm{min}$ for melting point determination.

Stability Tests. Chemical stability of each sample was determined by adding a small amount of freshly synthesized M-HAF-2 (5-10 mg) into different vials containing $2 \mathrm{~mL}$ of solvent. The MOF powders were soaked for 1 week after which they were isolated by centrifugation, washed with acetone three times, and dried under vacuum at room temperature. The resultant samples were analyzed by PXRD and compared to the pristine MOFs.

Thermal stability of M-HAF-2 was assessed by in situ variable temperature PXRD experiments. A small amount of MOF powders was added into a 1-mm glass capillary (Hampton Research). The measurements were performed using a Bruker Microstar APEX II CCD diffractometer equipped with $\mathrm{Cu} \mathrm{K} \alpha$ radiation $(\lambda=1.54178 \AA)$. 
Scanning electron microscopy imaging (SEM). The dry MOF powders were suspended in ethanol and deposited onto silicon chips with $5 \times 5 \mathrm{~mm}$ dimensions on top of conductive carbon tape. SEM images were obtained using a Zeiss Sigma 500 scanning electron microscope (Zeiss) at an accelerating voltage of $1 \mathrm{kV}$ to $1.5 \mathrm{kV}$ using a $30-\mu \mathrm{m}$ aperture with ETD detector.

Zeta Potential Measurements. Approximately $1 \mathrm{mg}$ of M-HAF-2 (M = Fe, In, and Ga) powders were suspended in $1 \mathrm{~mL}$ of aqueous solution at different $\mathrm{pH}$ values. The zeta potentials of M-HAF2 MOFs in different $\mathrm{pH}$ solutions were determined using a Zetasizer Nano ZS90 (Malvern Instruments). Experimental runs were performed using an automatic collection mode.

Dye uptake of Fe-HAF-2. In a typical experimental set-up for dye uptake study, 5 mg of FeHAF-2 were dispersed in $20 \mathrm{~mL}$ of $10 \mathrm{ppm}$ aqueous dye solutions. Absorption of the supernatant solution was monitored by UV-vis absorption spectroscopy over the time.

Postsynthetic Cation Exchange of M-HAF-2. 5 mg of as-synthesized M-HAF-2 and selected metal salts were added to $2 \mathrm{~mL}$ DEF in a 1-dram vial and sonicated for $10 \mathrm{~min}$. Then, the solution was heated in an oven at $80{ }^{\circ} \mathrm{C}$ for $48 \mathrm{~h}$. After cooling to $25^{\circ} \mathrm{C}$, the resultant solid was isolated by centrifugation, washed with fresh DEF $(3 \times 1 \mathrm{~mL})$, and acetone $(3 \times 1 \mathrm{~mL})$.

Inductively Coupled Plasma Mass Spectrometry (ICP-MS). The MOF samples were digested in $70 \%$ nitric acid and heated at $80{ }^{\circ} \mathrm{C}$ for $12 \mathrm{~h}$. After filtration through a syringe filter $(<0.2 \mu \mathrm{m})$, the solution was diluted with water so that the final concentration of nitric acid was 0.7\% by volume. All samples were analyzed for iron (Fe), indium (In) and gallium (Ga) content using a NexION 2000 ICP-MS. The reported values are the average of triplicate values. The calibration curve was established using a standard solution with a dwell time of 50 ms, thirty sweeps, and three replicates with background correction. 


\section{RESULTS AND DISCUSSION}

Synthesis and Structure of M-HAF-2. All members of the M-HAF-2 library were synthesized by combining the $\mathrm{H}_{4} \mathrm{TPTH}$ linker with the appropriate trivalent metal salt $\left(\mathrm{FeCl}_{3}, \mathrm{GaCl}_{3}\right.$ or $\left.\mathrm{InBr}_{3}\right)$ in a mixture of DEF and ACN at elevated temperature (60-100 $\left.{ }^{\circ} \mathrm{C}\right)$. All three M-HAF-2 species were isolated as $\leq 20 \mu \mathrm{m}$-long microcrystals with a hexagonal rod-like morphology (Figure S2) that was quite distinct from the cube-shaped Fe-HAF-1 crystals. These observations suggested that M-HAF-2 were likely not isoreticular with Fe-HAF-1. Indeed, 3DED and powder X-ray diffraction (PXRD) analysis of Fe-HAF-2, In-HAF-2 and Ga-HAF-2 frameworks, which were determined to be isostructural, indicated a trigonal space group (Figure S3\&4 and Figure 2a). The porosities of M-HAF-2 frameworks were investigated by $\mathrm{N}_{2}$ adsorption measurements at $77 \mathrm{~K}$. As shown in Figure 2b, the $\mathrm{N}_{2}$ sorption of Fe-HAF-2 and Ga-HAF-2 exhibited a reversible type II behavior and the calculated Brunauer-Emmett-Teller (BET) surface areas were $647 \mathrm{~m}^{2} / \mathrm{g}$ and 501 $\mathrm{m}^{2} / \mathrm{g}$, respectively. Despite In-HAF-2 being isostructural with Fe-HAF-2 and Ga-HAF-2, In-HAF2 exhibited negligible $\mathrm{N}_{2}$ uptake at $77 \mathrm{~K}$, suggestive of reduced mechanical stability (Figure S5).
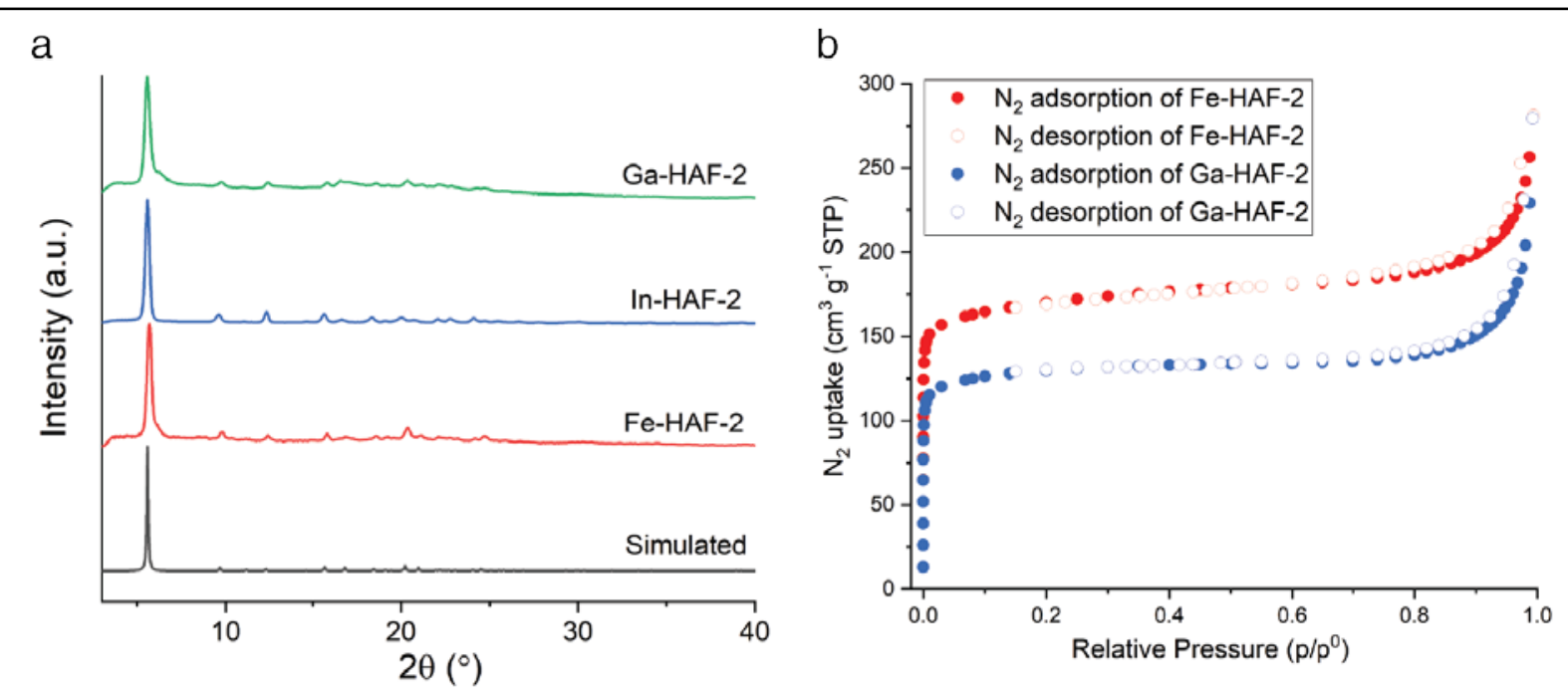

Figure 2. a) PXRD patterns of Fe-HAF-2, In-HAF-2, and Ga-HAF-2. b) $\mathrm{N}_{2}$ isotherms of FeHAF-2 and Ga-HAF-2 measured at $77 \mathrm{~K}$. 
M-HAF-2 crystals were too small for single-crystal X-ray diffraction experiments. However, we were able to use continuous rotation electron diffraction (cRED) methods to determine the atomic structure of Fe-HAF-2 $a b$ initio, with further refinement affording the final structural models (Figure 3) with R1 value converged to 0.209 (refinement details shown in Table S1). The unit cell parameters obtained from the cRED data were further refined against PXRD data by using the Pawley method (Table S1), which converged to $a=18.263(2) \AA$ and $c=16.177(2) \AA$ (Table

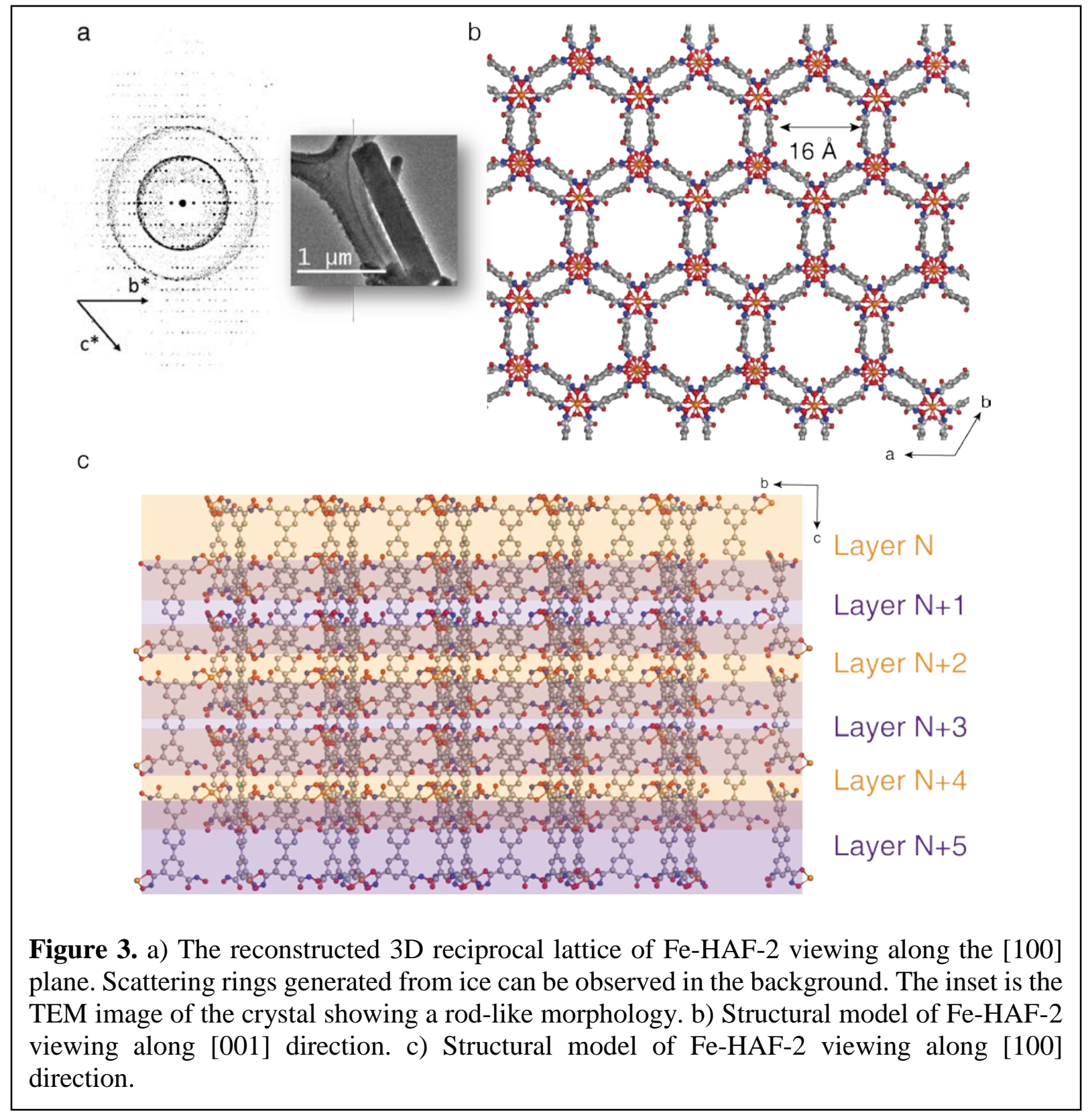


S2). Refinement of the PXRD pattern with the determined single crystal structure by cRED captures all observed diffraction peaks (Figure S4), confirming the phase-pure nature of the materials synthesized.

Fe-HAF-2 crystallizes in the trigonal space group $P \overline{3} c 1$, whereby each $\mathrm{Fe}^{3+}$ cation is coordinated by three hydroxamate groups as a single node in an octahedral geometry. Interestingly, only two of the four hydroxamate/hydroxamic acid groups in each linker are observed to participate in $\mathrm{Fe}^{3+}$ coordination to form 2D hexagonal layers (Figure 3b); these 2D layers are tightly interpenetrated along the c-axis as shown in Figure 3c. As viewed down the $c$ axis, the 3D framework is composed of double-walled hexagonal pores with an accessible pore diameter of $16 \AA$ (Figure 3b).

To describe the Fe-HAF-2 structure in more detail, it is useful to consider the framework as being composed of even- $(\mathrm{N}, \mathrm{N}+2, \mathrm{~N}+4 \ldots)$ and odd-numbered $(\mathrm{N}+1, \mathrm{~N}+3, \mathrm{~N}+5 \ldots)$ hexagonal layers (Figures 3 and 4). Each even (or odd) layer has the height of a single $\mathrm{H}_{4} \mathrm{TPTH}$ linker and is formed in the $b c$ plane, wherein the linkers are interconnected by coordination between $\mathrm{Fe}^{3+}$ ions and two hydroxamate groups on each linker (Figure 4a). Then, consecutive even- (or odd-) numbered layers are joined by three pairs of $\mathrm{H}$-bonds $(\mathrm{N} \ldots \mathrm{O}=2.6 \AA$ and $\mathrm{O} \ldots \mathrm{O}=2.6 \AA$ ) between metal-coordinated and free hydroxamatic acid groups. The intralayer metal-linker interactions and the interlayer H-bonding interactions thus generate a continuously bonded 3D framework, which, on its own, would likely not be sufficiently stable as a permanently porous MOF (due to the presumed weakness of H-bonding interactions).

Yet, an inspection of the Fe-HAF-2 structure shows that the adjacent even-numbered layers (N and $\mathrm{N}+2$ in Figure 4b) are also connected to one another by an odd-numbered layer (N+1 in Figure 4b) that spans the $\mathrm{N}-\mathrm{to}-\mathrm{N}+2$ interface. This interpenetration by the $\mathrm{N}+1$ layer is stabilized by a combination of non-covalent interactions: first, the terminal phenyl groups of each linker in the 
$\mathrm{N}+1$ layer form $\pi-\pi$ interactions (highlighted in purple in Figure 4b) with the terminal phenyl groups in the $\mathrm{N}$ and $\mathrm{N}+2$ layers. These interactions yield a continuous, staggered $\pi$-stacking pattern directed along the $c$ axis, creating a double wall that surrounds the hexagonal pores. Second, the two free hydroxamate groups in each linker in the $\mathrm{N}+1$ layer form additional H-bonds with the metal-coordinated hydroxamate groups in the $\mathrm{N}$ and $\mathrm{N}+2$ layers while the metal-coordinated hydroxamate groups in the same linker are H-bonded to free hydroxamate groups in the $\mathrm{N}$ and $\mathrm{N}+2$ layers $(\mathrm{N} \cdots \mathrm{O}=3.2 \AA$ ) (Figure $4 \mathrm{~b}$ ). In combination, the $\pi$ - $\pi$ and the H-bonding interactions afford a cooperative network of non-covalent bonds of remarkably high density along the $c$ axis (Figure 4c). In fact, each Fe-tris-hydroxamate node (or SBU) is involved in a total of nine H-bonds to the surrounding free hydroxamic acid groups through the participation of six coordinated oxygen atoms and three uncoordinated nitrogen atoms from the three hydroxamate groups (Figure 4c). To the best of our knowledge, this is the first observation of an SBU-templated H-bonding network within MOFs, which remarkably involves all twelve heteroatoms on each TPTH linker. Although there are MOFs featuring free carboxylic acid groups that participate in secondary Hbonds, these interactions are limited in terms of their valency and not crucial for the overall stability of the framework. ${ }^{47}$ Ultimately, the increased "bite angle" of hydroxamic acid and its elevated $p \mathrm{~K}_{\mathrm{a}}$ compared to the carboxylic acid group is responsible for its ability to participate in more extensive H-bonding interactions.

Comparison of the Fe-HAF-2 and Fe-HAF-1 structures. With the detailed structure of Fe-HAF2 in hand, we can attempt to rationalize why it is not isoreticular with its cubic predecessor FeHAF-1, which is formed exclusively through bidentate Fe-hydroxamate coordination bonds between BPTH linkers. Given that both Fe-HAF-1 and Fe-HAF-2 are obtained under similar 


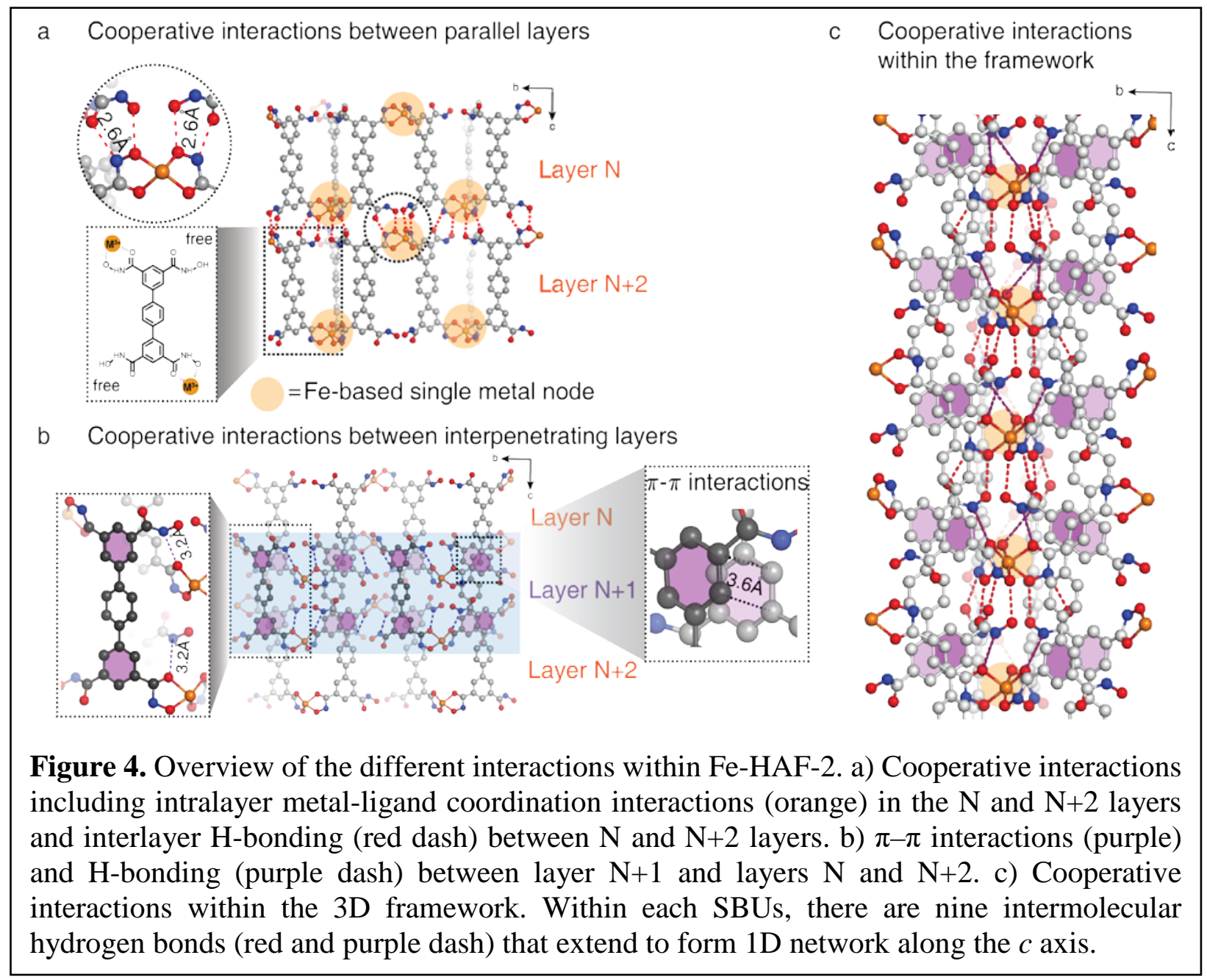

solvothermal synthesis conditions, they must both represent thermodynamic products that minimize the total free energy of bonds formed in the lattice. It then follows that the total aggregate free energy of $\pi-\pi$ and H-bonding interactions in Fe-HAF-2 must be more favorable than the total free energy of $\mathrm{Fe}^{3+}$-hydroxamate interactions that are foregone (two per TPTH linker) by not forming a cubic lattice. On a per-linker basis, the new bonds made in Fe-HAF-2 compared to FeHAF-1 amount to one phenyl-phenyl $\pi$ - $\pi$ stacking interaction (two total aromatic $\pi$ - $\pi$ interactions shared by two linkers) and six H-bonds (twelve total unique H-bonds shared with an adjacent linker), which must overcome the loss of two bidentate $\mathrm{Fe}^{3+}$-hydroxamate bonds. Given that metalcoordination interactions (particularly those of Fe-hydroxamate chelates) can be assumed to be 
considerably stronger than a similar number of $\pi$ - $\pi$ and H-bonding interactions, it is, at a first glance, surprising TPTH does not have form an isoreticular cubic lattice as BPTH. In the absence of an accurate knowledge on the energetic contributions of individual metal coordination and noncovalent bonds, particularly in the context of an extended 3D lattice, we ascribe the thermodynamic favorability of the trigonal Fe-HAF-2 lattice to the extensive cooperativity/synergy between the $\pi-\pi$ and H-bonding interactions (Figure 4c).

The converse question of why BPTH does not form an isoreticular, trigonal lattice as TPTH is easier to explain. BPTH can theoretically form the same layered, 3D arrangement shown in Figure 4a (obtained through $\mathrm{H}$-bonding between $\mathrm{N}$ and $\mathrm{N}+2$ layers). Yet, the biphenyl linker is not sufficiently long to span across the adjacent even numbered layers to enable interpenetration through $\pi-\pi$ and H-bonding interactions, which renders the metal-only interconnected cubic lattice the most thermodynamically favorable option.

Stability of M-HAF-2. We next examined how the unusual bonding network of M-HAF-2 affected its physical and chemical stability, particularly in aqueous environments. The thermal stability of M-HAF-2 was evaluated by TGA and in situ variable temperature PXRD. The TGA curves displayed no significant weight loss up to $200{ }^{\circ} \mathrm{C}$ for all three samples (Figure S6). The PXRD patterns (Figure 5a and Figure S7) indicated that M-HAF-2 frameworks retained their crystallinity up to at least $175^{\circ} \mathrm{C}$ (the instrument limit), which is consistent with the TGA results. Notably, M-HAF-2 also demonstrated excellent chemical stability in a wide range of aqueous solutions and $\mathrm{pH}$ values. As shown in Figure 5b, Fe-HAF-2 remained crystalline under both highly acidic conditions ( $\mathrm{pH}$ 1) and basic conditions ( $\mathrm{pH}$ 13). Compared to Fe-HAF-1, Fe-HAF-2 was found to be slightly less stable under basic conditions compared to Fe-HAF-1 (which is stable even 

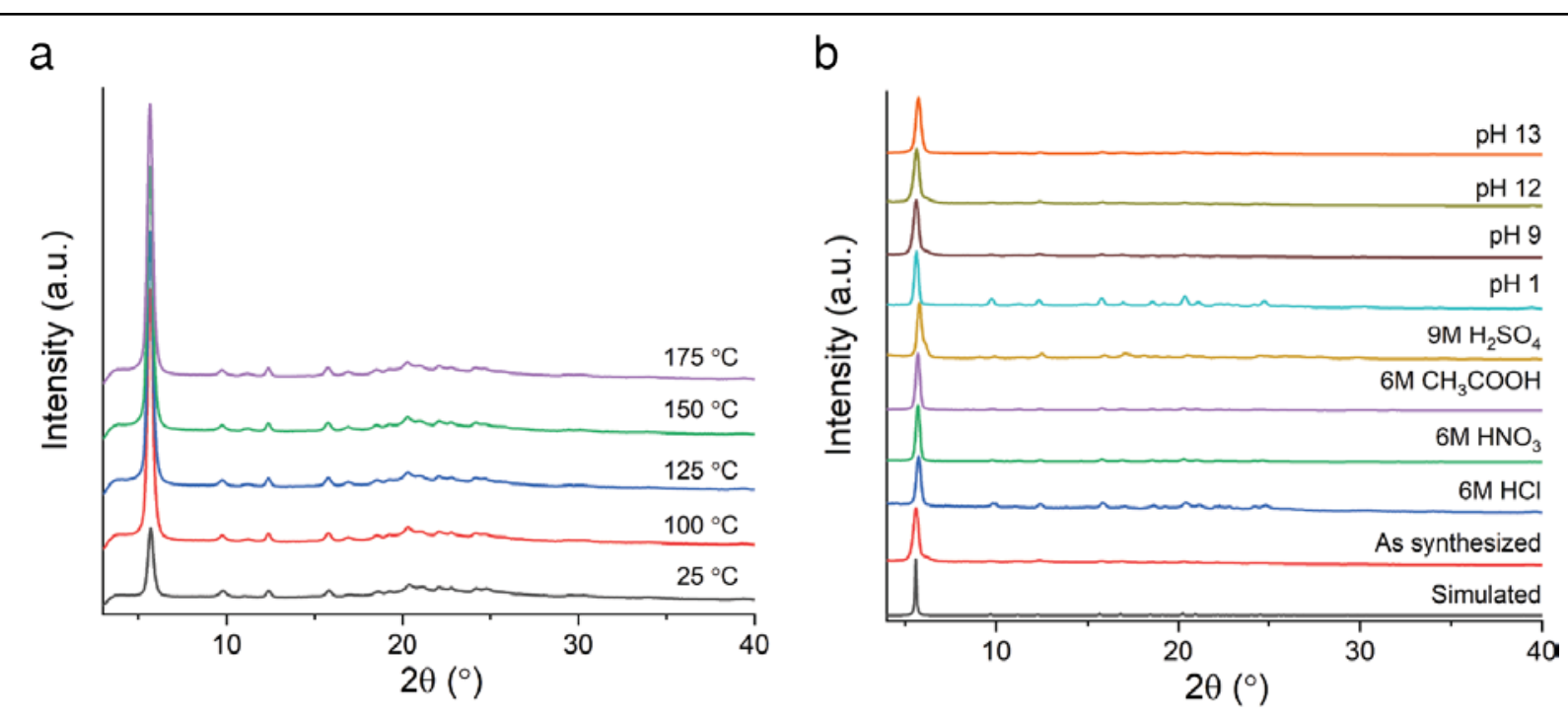

Figure 5. a) In situ temperature-dependent PXRD patterns of Fe-HAF-2 from $25-175^{\circ} \mathrm{C}$. b) PXRD patterns of Fe-HAF-2 after exposure to different aqueous solutions.

in $5 \mathrm{M} \mathrm{NaOH}$; we attribute this to the deprotonation of the free hydroxamate groups and the resulting loss of H-bonding interactions. Conversely, Fe-HAF-2 maintained its crystalline structure even after immersion into $6 \mathrm{M} \mathrm{HNO}_{3}, 9 \mathrm{M} \mathrm{H}_{2} \mathrm{SO}_{4}, 6 \mathrm{M} \mathrm{HCl}$, and $6 \mathrm{M}$ acetic acid (Figure 5b), consistent with the retention of the H-bonding network. The chemical stability of Fe-HAF-2 compares very favorably to the other chemically stable Fe-based MOFs such as Fe-HAF-1,MIL$100^{48}, \mathrm{PCN}-250^{49}$, and PCN-600. ${ }^{50} \mathrm{Ga}-\mathrm{HAF}-2$ and In-HAF-2 were found to be less chemically stable than Fe-HAF-2, likely owing to the reduced stabilities of $\mathrm{Ga}^{3+}$ - and $\mathrm{In}^{3+}$-tris-hydroxamates nodes, but both frameworks maintained crystallinity after soaking in aqueous solutions from $\mathrm{pH} 2$ to 11 for at least 1 week (Figure S8). These experiments illustrate the high thermal and chemical stability of M-HAF-2 in a range of aqueous environments, suggesting that these materials are chemically robust for potential applications such as aqueous chemical separations or gas adsorption. 
Dye uptake of Fe-HAF-2. The aqueous stability of M-HAF-2, coupled with the presence of non-metal-bound hydroxamate groups, suggested that these MOFs could be well-suited for ionic separations. Zeta potential measurements indicated and the isoelectric point (pI) of 5.3 for FeHAF-2 (Figure S9). Above pH 5.3, Fe-HAF-2 becomes negatively charged, indicating that it should have favorable interactions with cationic guest molecules. We chose two cationic organic dyes (Methylene Blue $\left(\mathrm{MB}^{+}\right)$, Lauth’s Violet $\left(\mathrm{LV}^{+}\right)$), one neutral dye (neutral red (NR)), and two anionic organic dyes (Orange $\mathrm{G}\left(\mathrm{OG}^{2-}\right)$, and Acid Orange $6\left(\mathrm{AO6}^{-}\right)$) as model compounds to test the uptake selectivity and capacity of Fe-HAF-2s. The sizes of all of these dyes are smaller than the diameter of hexagonal pore channels to eliminate any steric limitations for uptake (Figure S10). As shown in Figure 6 and S11-12, the cationic species $\left(\mathrm{LV}^{+}\right.$and $\left.\mathrm{MLB}^{+}\right)$were sequestered rapidly (within tens of seconds to few minutes) by Fe-HAF-2, evidenced by the decrease in the absorbance of the solution, while both anionic dyes $\left(\mathrm{OG}^{2-}\right.$ and $\left.\mathrm{AO6}^{-}\right)$remained in solution. The neutral dye (NR) was also taken up by Fe-HAF-2, but the process was considerably slower (many minutes) compared to the cationic species (Figure S13). The slower rate of NR uptake can be attributed to its diffusion-limited uptake via $\pi-\pi$ interactions between NR and the framework, whereas the cationic dye uptake is driven by both electrostatic interactions and $\pi-\pi$ stacking. The selectivity of Fe-HAF-2 to bind cationic dyes over anionic and neutral dyes was further investigated by competition experiments. In a solution of equimolar (0.025 mmol) mixed dyes ( $\mathrm{MB}^{+}$and $\left.\mathrm{OG}^{2-}\right)$, the Fe-HAF-2 selectively removed more than $95 \%$ of the cationic dye $\left(\mathrm{MB}^{+}\right)$from the solution within 10 min while the anionic dye $\left(\mathrm{OG}^{2-}\right)$ remains the same concentration (Figure $\left.4 \mathrm{~b}\right)$. After dye 
uptake, the Fe-HAF-2 retained its crystallinity as indicated by PXRD measurements (Figure S14). Interestingly, Fe-HAF-2 sequestered 99\% of the cationic dyes $\left(\mathrm{LV}^{+}\right.$and $\left.\mathrm{MB}^{+}\right)$from solution within 10 min, far more rapidly than Fe-HAF-1 and most other reported anionic frameworks. ${ }^{51-52}$ To further explore the adsorption kinetics in Fe-HAF-2, the pseudo-second-order kinetic model ${ }^{53}$ was used to fit the adsorption of $\mathrm{MB}^{+}$over time with different initial concentrations (Figure S15). The linear form of the equation is:

$$
\frac{t}{q_{t}}=\frac{1}{h}+\frac{1}{q_{e}} t
$$

with

$$
h=k_{2} q_{e}^{2}
$$

where $h$ is the initial sorption rate; $t$ is the adsorption time (s), $q_{e}$ and $q_{t}$ are the amount of dye adsorbed at equilibrium and at time $t$ respectively $\left(\mathrm{mg} \cdot \mathrm{g}^{-1}\right)$, and $k_{2}$ is the rate constant for pseudo-
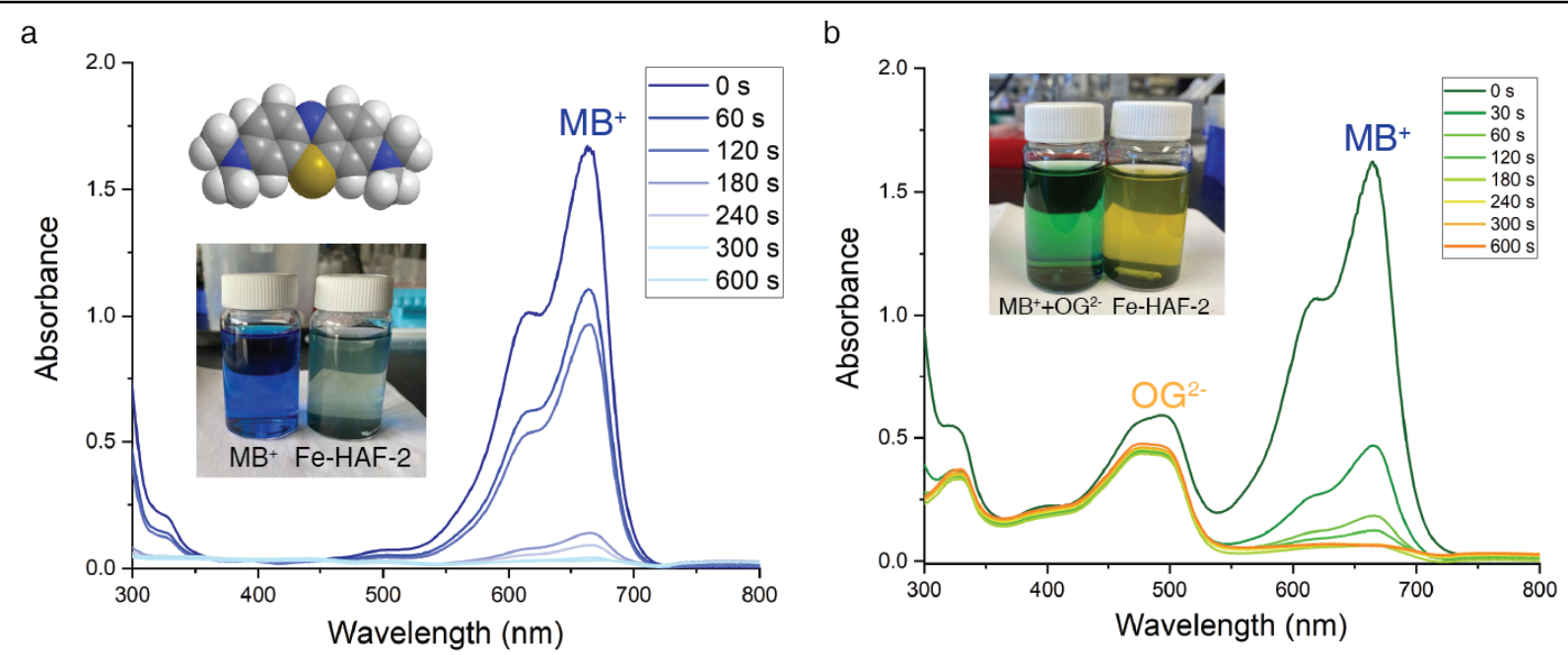

Figure 6. UV-vis spectra of Fe-HAF-2 uptake experiments with dyes: a) $10 \mathrm{ppm}$ of $\mathrm{MB}^{+}$, b) $10 \mathrm{ppm}$ of $\mathrm{OG}^{2-}$ and $\mathrm{MB}^{+}$in $20 \mathrm{~mL} \mathrm{H}_{2} \mathrm{O}$ with the presence of $5 \mathrm{mg}$ Fe-HAF-2 over $10 \mathrm{~min}$. 
second-order adsorption $\left(\mathrm{g} \cdot \mathrm{mg}^{-1} \cdot \mathrm{s}^{-1}\right) . k_{2}=\frac{\text { slope }^{2}}{\text { intercept }}$ when the $\frac{t}{q_{t}}$ is plotted against $t$. The calculated kinetic constants $\left(k_{2}\right)$ and initial sorption rate $(h)$ are summarized in Table S2. The pseudo second-order model showed a good fit with experimental data $\left(\mathrm{R}^{2}>0.99\right)$ across a series of initial dye concentrations from 10-40 ppm (Figure S15). The values of $q_{e, c a l}$ also appeared to be consistent with the experimental values of $q_{e}$. This finding suggests that the adsorption kinetics indeed followed the pseudo second-order model. The equilibrium adsorption capacity $\left(q_{e, c a l}\right)$ increased with increasing the initial concentration of $\mathrm{MB}^{+}$, attributed to the relatively strong driving force of the concentration gradient at high initial concentrations. Additionally, the $k_{2}\left(\mathrm{~g} \cdot \mathrm{mg}^{-1} \cdot \mathrm{s}^{-1}\right)$ values decreased from $4.38 \times 10^{-3}$ to $7.746 \times 10^{-5}$ with the increase of initial dye concentrations from $10 \mathrm{ppm}$ to $40 \mathrm{ppm}$, which can be ascribed to the lower competition for the adsorption surface sites at lower concentration. Compared with Fe-HAF-1, the presence of hydrogen bonding network in Fe-HAF-2 enables the $\mathrm{pH}$ dependent rapid uptake of cationic dyes that offer new potential for $\mathrm{pH}$ dependent chemical separations in porous materials.

Postsynthetic Metal Exchange of M-HAF-2. The presence of uncoordinated hydroxamate groups led us to examine if they could be modified post-synthetically with metal ions (e.g., additional $\mathrm{Fe}^{3+}$, lanthanide cations) under room temperature. However, PXRD measurements and 3DED of MOF samples even after the prolonged treatment with excess metal ions remained isostructural and indicated that the uncoordinated hydroxamate groups remain unreactive (Figure S16), likely owing to the fact that they are tightly sequestered within the cooperative H-bonding framework.

Post-synthetic exchange (PSE) of metal centers at SBUs in MOFs is a powerful approach for expanding the scope and functionality of these materials ${ }^{54-57}$. Metal-exchange reactions typically 
are kinetically and thermodynamically controlled by the stability constants of the substituting cations and the strength of the metal-ligand coordination interaction at the inorganic node. To date, most examples of MOFs have focused on labile SBUs containing soft metal ions that are amenable to transmetalation because they are more prone to hydrolysis and metal replacement. ${ }^{58-61}$ In contrast, robust MOFs with SBUs featuring strong metal binding affinities are less likely to undergo metal exchange at the node and can induce the undesired formation of an oxide coating. ${ }^{62}$ Interestingly, we found that despite the high chemical and thermal stability of M-HAF-2, the metals in the MOFs are still labile enough to undergo transmetalation while preserving the overall structure and crystallinity.

We first tested the transmetalation of In-HAF-2 in the presence of $\mathrm{Ga}^{3+}$ via the PSE approach. After immersing In-HAF-2 in a DEF solution containing $\mathrm{GaCl}_{3}$ at $80{ }^{\circ} \mathrm{C}$ for $48 \mathrm{~h}$, followed by multiple wash steps using fresh DEF and acetone to remove the excess metal ions, we observed a color change (from white to ivory) of the bulk powder samples as shown in Figure 7b. In addition to the observed color change, we further characterized the bulk MOF samples by ICP-MS, SEM, and PXRD. The PXRD indicated that the frameworks (In-HAF-2) maintained high crystallinity with no changes in the lattice symmetry (Figure 7a) after metal exchange with $\mathrm{Ga}^{3+}$. EM images indicated that the MOF powder retained its rod-shaped morphology for all the tested samples (Figures 7c, d). As shown in Table 1, the ICP-MS of digested MOF samples after PSE indicate that transmetalation efficiency depends on the metal ratio of In and Ga in reaction. With higher $\mathrm{Ga}^{3+}$ ratio, the bulk MOF samples after PSE showed higher $\mathrm{Ga}^{3+}$ content. The metal exchange percentage of MOF samples (In/Ga-1 to In/Ga-4) varied from 53.8\% to $93.5 \%$ in correspondence to the metal ratio of In to Ga from 1:1 to 1:10 used during PSE. It is important to note that the ICPMS data only reflect the absolute metal concentration in bulk powders, the distribution of metals 


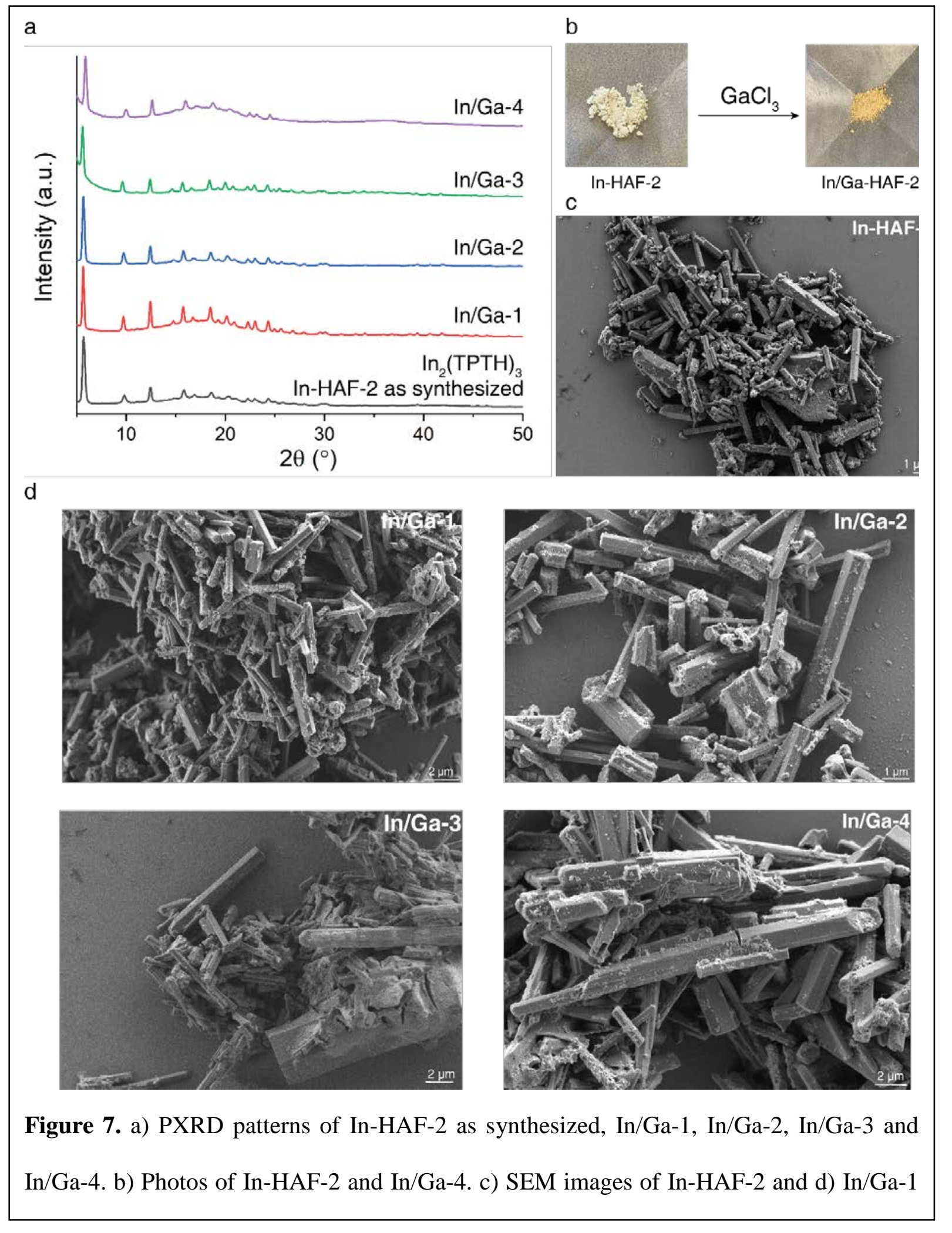


within individual crystallites is still unknown and requires further study. Moreover, the $\mathrm{N}_{2}$ sorption of In/Ga-4 after PSE showed a BET surface area of $65 \mathrm{~m}^{2} / \mathrm{g}$ (Figure S17), which is larger than the parent framework (In-HAF-2) and smaller than Ga-HAF-2, further confirming the incomplete transmetalation and potentially reduced stability of In/Ga-4 during the activation process compared with Ga-HAF-2. The In-HAF-2 was also observed to undergo exchange upon treatment with $\mathrm{FeCl}_{3}$ in a concentration-dependent manner without losing the crystalline structure and rodshaped morphology of the microcrystals (Figure S18). Significant color change (from white to orange) of the bulk powders was observed (Figure S18) and the extent of metal exchange was 60 $\%, 76 \%, 89 \%$, and $89 \%$ for MOF samples prepared with In/Fe metal ratios of 1:1, 1:2.5, 1:5 and 1:10, respectively (summarized in Table S3). $\mathrm{N}_{2}$ adsorption measurements of $\mathrm{In} / \mathrm{Fe}-4$ revealed a BET surface area of $97 \mathrm{~m}^{2} / \mathrm{g}$ (Figure S19). Similarly, the transmetalation of Ga-HAF-2 with $\mathrm{Fe}^{3+}$ was also possible (summarized in Table S4), but the framework was found to lose crystallinity at high Fe/Ga ratios (Figure S20). It is worth noting that the incomplete transmetalation of M-HAF2 has been commonly observed in other mixed-metal-MOF systems using PSE strategy. ${ }^{63}$ These results demonstrate that M-HAF-2 can undergo facile post-synthetic metal exchange, which likely stems from their robust non-covalent bonding frameworks that help maintain the lattice structure during metal substitution reactions. M-HAF-2 also represents one of the few MOFs that can undergo post-synthetic metathesis between trivalent metal ions..$^{59,64}$

Table 1 Theoretical transmetalation percentage of In-HAF-2 based on the ICP-MS of digested MOF samples after PSE with the addition of different amount of $\mathrm{GaCl}_{3}$

\begin{tabular}{|l|l|l|l|l|}
\hline $\begin{array}{l}\text { Sample } \\
\text { name }\end{array}$ & $\begin{array}{l}\text { Theoretical } \\
\text { metal ratio in } \\
\text { reaction }\end{array}$ & $\begin{array}{l}\text { Normalized metal } \\
\text { ratio after digestion } \\
\text { for ICP-MS }\end{array}$ & $\begin{array}{l}\text { Empirical formula } \\
\text { of MOF based on } \\
\text { ICP-MS }\end{array}$ & $\begin{array}{l}\text { Transmetalation } \\
\text { percentage of In- } \\
\text { HAF-2 }\end{array}$ \\
\hline
\end{tabular}




\begin{tabular}{|c|c|c|c|c|}
\hline $\mathrm{In} / \mathrm{Ga}-1$ & In $: G a=1: 1$ & 1: 1.2 & 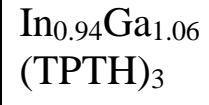 & $53.8 \%$ \\
\hline In/Ga-2 & In $: G a=1: 2.5$ & $1: 2.3$ & $\begin{array}{l}\mathrm{In}_{0.61} \mathrm{Ga}_{1.39} \\
(\mathrm{TPTH})_{3}\end{array}$ & $69.7 \%$ \\
\hline In/Ga-3 & In: $\mathrm{Ga}=1: 5$ & $1: 3.4$ & $\begin{array}{l}\mathrm{In}_{0.46} \mathrm{Ga}_{1.54} \\
(\mathrm{TPTH})_{3}\end{array}$ & $77.1 \%$ \\
\hline In/Ga-4 & In $: G a=1: 10$ & $1: 14.8$ & $\begin{array}{l}\mathrm{In}_{0.13 \mathrm{Ga}_{1.87}} \\
(\mathrm{TPTH})_{3}\end{array}$ & $93.5 \%$ \\
\hline
\end{tabular}

\section{CONCLUSIONS}

In summary, we have developed a new series of hydroxamate-based MOFs, M-HAF-2 (M=Fe, Ga or In), by using a tetratopic hydroxamate-based linker, $\mathrm{H}_{4} \mathrm{TPTH}$. The M-HAF-2 frameworks are formed through a highly cooperative, protein-like network of metal-linker coordination, $\pi-\pi$, and H-bonding interactions, and present an unusual topology of interpenetrated hcb-a net, instead of the originally expected isoreticular expansion of Fe-HAF-1. The M-HAF-2 MOFs exhibits high thermal and chemical stability in a range of aqueous environments and demonstrates highly selective and rapid uptake of dye molecules in a charge-selective fashion. Moreover, the synergistic effect of three different types of interactions within M-HAF-2 gives rise to a highly robust bonding framework that enables facile post-synthetic metal exchange at the single-metal nodes without structural collapse. Overall, our study shows the great utility of new, non-canonical 
metal-coordinating functionalities such as the hydroxamic acid in the discovery of new bonding and topological patterns in MOFs.

\title{
AUTHOR INFORMATION
}

\section{Author Contributions}

The manuscript was written through contributions of all authors. All authors have given approval to the final version of the manuscript. $¥$ These authors contributed equally. (match statement to author names with a symbol)

\begin{abstract}
ABBREVIATIONS
CCR2, CC chemokine receptor 2; CCL2, CC chemokine ligand 2; CCR5, CC chemokine receptor 5; TLC, thin layer chromatography.
\end{abstract}

\section{REFERENCES}

1. Emergence of Metal-Organic Frameworks. In Introduction to Reticular Chemistry, 2019; pp 1-27.

2. $\quad$ Introduction to Metal-Organic Frameworks. Chem. Rev. 2012, 112 (2), 673-674.

3. Moghadam, P. Z.; Li, A.; Wiggin, S. B.; Tao, A.; Maloney, A. G. P.; Wood, P. A.; Ward, S. C.; Fairen-Jimenez, D., Development of a Cambridge Structural Database Subset: A Collection of Metal-Organic Frameworks for Past, Present, and Future. Chem. Mater. 2017, 29 (7), 2618-2625.

4. Li, H.; Li, L.; Lin, R.-B.; Zhou, W.; Zhang, Z.; Xiang, S.; Chen, B., Porous metal-organic frameworks for gas storage and separation: Status and challenges. EnergyChem 2019, 1 (1), 100006.

5. Petit, C., Present and future of MOF research in the field of adsorption and molecular separation. Current Opinion in Chemical Engineering 2018, 20, 132-142.

6. $\quad$ Li, H.; Wang, K.; Sun, Y.; Lollar, C. T.; Li, J.; Zhou, H.-C., Recent advances in gas storage and separation using metal-organic frameworks. Mater. Today 2018, 21 (2), 108-121. 7. $\quad$ Liao, P.-Q.; Huang, N.-Y.; Zhang, W.-X.; Zhang, J.-P.; Chen, X.-M., Controlling guest conformation for efficient purification of butadiene. Science 2017, 356 (6343), 1193-1196.

8. Della Rocca, J.; Liu, D.; Lin, W., Nanoscale Metal-Organic Frameworks for Biomedical Imaging and Drug Delivery. Acc. Chem. Res. 2011, 44 (10), 957-968. 
9. $\quad$ Wu, M.-X.; Yang, Y.-W., Metal-Organic Framework (MOF)-Based Drug/Cargo Delivery and Cancer Therapy. Adv. Mater. 2017, 29 (23), 1606134.

10. Dolgopolova, E. A.; Rice, A. M.; Martin, C. R.; Shustova, N. B., Photochemistry and photophysics of MOFs: steps towards MOF-based sensing enhancements. Chem. Soc. Rev. 2018, 47 (13), 4710-4728.

11. Tchalala, M. R.; Bhatt, P. M.; Chappanda, K. N.; Tavares, S. R.; Adil, K.; Belmabkhout, Y.; Shkurenko, A.; Cadiau, A.; Heymans, N.; De Weireld, G.; Maurin, G.; Salama, K. N.; Eddaoudi, M., Fluorinated MOF platform for selective removal and sensing of SO2 from flue gas and air. Nature Communications 2019, 10 (1), 1328.

12. Liao, P.-Q.; Shen, J.-Q.; Zhang, J.-P., Metal-organic frameworks for electrocatalysis. Coord. Chem. Rev. 2018, 373, 22-48.

13. Goetjen, T. A.; Liu, J.; Wu, Y.; Sui, J.; Zhang, X.; Hupp, J. T.; Farha, O. K., Metalorganic framework (MOF) materials as polymerization catalysts: a review and recent advances. Chem. Commun. 2020, 56 (72), 10409-10418.

14. Zhu, J.; Usov, P. M.; Xu, W.; Celis-Salazar, P. J.; Lin, S.; Kessinger, M. C.; LandaverdeAlvarado, C.; Cai, M.; May, A. M.; Slebodnick, C.; Zhu, D.; Senanayake, S. D.; Morris, A. J., A New Class of Metal-Cyclam-Based Zirconium Metal-Organic Frameworks for CO2 Adsorption and Chemical Fixation. Journal of the American Chemical Society 2018, 140 (3), 993-1003.

15. Rosi, N. L.; Eckert, J.; Eddaoudi, M.; Vodak, D. T.; Kim, J.; O'Keeffe, M.; Yaghi, O. M., Hydrogen Storage in Microporous Metal-Organic Frameworks. Science 2003, 300 (5622), 11271129.

16. Park, K. S.; Ni, Z.; Côté, A. P.; Choi, J. Y.; Huang, R.; Uribe-Romo, F. J.; Chae, H. K.; O’Keeffe, M.; Yaghi, O. M., Exceptional chemical and thermal stability of zeolitic imidazolate frameworks. Proceedings of the National Academy of Sciences 2006, 103 (27), 10186-10191. 17. Zhang, J.-P.; Zhang, Y.-B.; Lin, J.-B.; Chen, X.-M., Metal azolate frameworks: from crystal engineering to functional materials. Chem. Rev. 2012, 112 (2), 1001-1033.

18. Serre, C.; Millange, F.; Thouvenot, C.; Noguès, M.; Marsolier, G.; Louër, D.; Férey, G., Very Large Breathing Effect in the First Nanoporous Chromium(III)-Based Solids: MIL-53 or $\mathrm{CrIII}(\mathrm{OH}) \cdot\{\mathrm{O} 2 \mathrm{C}-\mathrm{C} 6 \mathrm{H} 4-\mathrm{CO} 2\} \cdot\{\mathrm{HO} 2 \mathrm{C}-\mathrm{C} 6 \mathrm{H} 4-\mathrm{CO} 2 \mathrm{H}\} \mathrm{x} \cdot \mathrm{H} 2 \mathrm{Oy}$. Journal of the American Chemical Society 2002, 124 (45), 13519-13526.

19. Férey, G.; Mellot-Draznieks, C.; Serre, C.; Millange, F.; Dutour, J.; Surblé, S.; Margiolaki, I., A Chromium Terephthalate-Based Solid with Unusually Large Pore Volumes and Surface Area. Science 2005, 309 (5743), 2040-2042.

20. Cavka, J. H.; Jakobsen, S.; Olsbye, U.; Guillou, N.; Lamberti, C.; Bordiga, S.; Lillerud, K. P., A New Zirconium Inorganic Building Brick Forming Metal Organic Frameworks with Exceptional Stability. Journal of the American Chemical Society 2008, 130 (42), 13850-13851. 21. Mondloch, J. E.; Bury, W.; Fairen-Jimenez, D.; Kwon, S.; DeMarco, E. J.; Weston, M. H.; Sarjeant, A. A.; Nguyen, S. T.; Stair, P. C.; Snurr, R. Q.; Farha, O. K.; Hupp, J. T., VaporPhase Metalation by Atomic Layer Deposition in a Metal-Organic Framework. Journal of the American Chemical Society 2013, 135 (28), 10294-10297.

22. Yuan, D.; Zhao, D.; Sun, D.; Zhou, H.-C., An Isoreticular Series of Metal-Organic Frameworks with Dendritic Hexacarboxylate Ligands and Exceptionally High Gas-Uptake Capacity. Angew. Chem. Int. Ed. 2010, 49 (31), 5357-5361.

23. Guillerm, V.; Eddaoudi, M., The Importance of Highly Connected Building Units in Reticular Chemistry: Thoughtful Design of Metal-Organic Frameworks. Acc. Chem. Res. 2021, 54 (17), 3298-3312. 
24. Muldoon, P. F.; Liu, C.; Miller, C. C.; Koby, S. B.; Gamble Jarvi, A.; Luo, T.-Y.; Saxena, S.; O’Keeffe, M.; Rosi, N. L., Programmable Topology in New Families of Heterobimetallic Metal-Organic Frameworks. Journal of the American Chemical Society 2018, 140 (20), 6194-6198.

25. Li, R.-J.; Li, M.; Zhou, X.-P.; Li, D.; O'Keeffe, M., A highly stable MOF with a rod SBU and a tetracarboxylate linker: unusual topology and CO2 adsorption behaviour under ambient conditions. Chem. Commun. 2014, 50 (31), 4047-4049.

26. Xue, D.-X.; Cadiau, A.; Weseliński, Ł. J.; Jiang, H.; Bhatt, P. M.; Shkurenko, A.; Wojtas, L.; Zhijie, C.; Belmabkhout, Y.; Adil, K.; Eddaoudi, M., Topology meets MOF chemistry for pore-aperture fine tuning: ftw-MOF platform for energy-efficient separations via adsorption kinetics or molecular sieving. Chem. Commun. 2018, 54 (49), 6404-6407.

27. Guillerm, V.; Weseliński, Ł. J.; Belmabkhout, Y.; Cairns, A. J.; D'Elia, V.; Wojtas, Ł.; Adil, K.; Eddaoudi, M., Discovery and introduction of a $(3,18)$-connected net as an ideal blueprint for the design of metal-organic frameworks. Nature Chemistry 2014, 6 (8), 673-680.

28. Martell, A. E., Catalytic effects of metal chelate compounds. Pure Appl. Chem. 1968, 17 (1), 129-178.

29. Almhjell, P. J.; Mills, J. H., Metal-chelating non-canonical amino acids in metalloprotein engineering and design. Current Opinion in Structural Biology 2018, 51, 170-176.

30. Abrahams, B. F.; Hudson, T. A.; McCormick, L. J.; Robson, R., Coordination Polymers of 2,5-Dihydroxybenzoquinone and Chloranilic Acid with the (10,3)-a Topology. Crystal Growth \& Design 2011, 11 (7), 2717-2720.

31. Nakabayashi, K.; Ohkoshi, S.-i., Monometallic Lanthanoid Assembly Showing Ferromagnetism with a Curie Temperature of 11 K. Inorg. Chem. 2009, 48 (18), 8647-8649.

32. Shota, M.; Teppei, Y.; Hiroshi, K., Crystal Structure and Proton Conductivity of a Onedimensional Coordination Polymer, $\{\mathrm{Mn}(\mathrm{DHBQ})(\mathrm{H} 2 \mathrm{O}) 2\}$. Chem. Lett. 2009, 38 (7), 654-655.

33. Abrahams, B. F.; Coleiro, J.; Ha, K.; Hoskins, B. F.; Orchard, S. D.; Robson, R., Dihydroxybenzoquinone and chloranilic acid derivatives of rare earth metals. J. Chem. Soc., Dalton Trans. 2002, (8), 1586-1594.

34. Hmadeh, M.; Lu, Z.; Liu, Z.; Gándara, F.; Furukawa, H.; Wan, S.; Augustyn, V.; Chang, R.; Liao, L.; Zhou, F.; Perre, E.; Ozolins, V.; Suenaga, K.; Duan, X.; Dunn, B.; Yamamto, Y.;

Terasaki, O.; Yaghi, O. M., New Porous Crystals of Extended Metal-Catecholates. Chem. Mater. 2012, 24 (18), 3511-3513.

35. Nguyen, N. T. T.; Furukawa, H.; Gándara, F.; Trickett, C. A.; Jeong, H. M.; Cordova, K. E.; Yaghi, O. M., Three-Dimensional Metal-Catecholate Frameworks and Their Ultrahigh Proton Conductivity. Journal of the American Chemical Society 2015, 137 (49), 15394-15397.

36. Matheu, R.; Gutierrez-Puebla, E.; Monge, M. Á.; Diercks, C. S.; Kang, J.; Prévot, M. S.; Pei, X.; Hanikel, N.; Zhang, B.; Yang, P.; Yaghi, O. M., Three-Dimensional Phthalocyanine Metal-Catecholates for High Electrochemical Carbon Dioxide Reduction. Journal of the American Chemical Society 2019, 141 (43), 17081-17085.

37. Liu, J.; Zhou, Y.; Xie, Z.; Li, Y.; Liu, Y.; Sun, J.; Ma, Y.; Terasaki, O.; Chen, L., Conjugated Copper-Catecholate Framework Electrodes for Efficient Energy Storage. Angew. Chem. Int. Ed. 2020, 59 (3), 1081-1086.

38. Crumbliss, A. L., Iron bioavailability and the coordination chemistry of hydroxamic acids. Coord. Chem. Rev. 1990, 105, 155-179.

39. Saha, R.; Saha, N.; Donofrio, R. S.; Bestervelt, L. L., Microbial siderophores: a mini review. Journal of Basic Microbiology 2013, 53 (4), 303-317. 
40. Al Shaer, D.; Al Musaimi, O.; de la Torre, B. G.; Albericio, F., Hydroxamate siderophores: Natural occurrence, chemical synthesis, iron binding affinity and use as Trojan horses against pathogens. European Journal of Medicinal Chemistry 2020, 208, 112791.

41. Neilands, J. B., Hydroxamic Acids in Nature. Science 1967, 156 (3781), 1443-1447.

42. Sugamata, K.; Takagi, C.; Awano, K.; Iihama, T.; Minoura, M., Structural analysis of and selective $\mathrm{CO} 2$ adsorption in mixed-ligand hydroxamate-based metal-organic frameworks. Dalton Transactions 2020, 49 (29), 9948-9952.

43. Chiong, J. A.; Zhu, J.; Bailey, J. B.; Kalaj, M.; Subramanian, R. H.; Xu, W.; Cohen, S. M.; Tezcan, F. A., An Exceptionally Stable Metal-Organic Framework Constructed from Chelate-Based Metal-Organic Polyhedra. J. Am. Chem. Soc. 2020, 142 (15), 6907-6912.

44. Padial, N. M.; Castells-Gil, J.; Almora-Barrios, N.; Romero-Angel, M.; da Silva, I.; Barawi, M.; García-Sánchez, A.; de la Peña O’Shea, V. A.; Martí-Gastaldo, C., Hydroxamate Titanium-Organic Frameworks and the Effect of Siderophore-Type Linkers over Their Photocatalytic Activity. Journal of the American Chemical Society 2019, 141 (33), 13124-13133. 45. Pereira, C. F.; Howarth, A. J.; Vermeulen, N. A.; Almeida Paz, F. A.; Tomé, J. P. C.; Hupp, J. T.; Farha, O. K., Towards hydroxamic acid linked zirconium metal-organic frameworks. Materials Chemistry Frontiers 2017, 1 (6), 1194-1199.

46. Beissel, T.; Powers, R. E.; Raymond, K. N., Symmetry-Based Metal Complex Cluster Formation. Angewandte Chemie International Edition in English 1996, 35 (10), 1084-1086.

47. Marsh, C.; Han, X.; Li, J.; Lu, Z.; Argent, S. P.; da Silva, I.; Cheng, Y.; Daemen, L. L.; Ramirez-Cuesta, A. J.; Thompson, S. P.; Blake, A. J.; Yang, S.; Schröder, M., Exceptional Packing Density of Ammonia in a Dual-Functionalized Metal-Organic Framework. Journal of the American Chemical Society 2021, 143 (17), 6586-6592.

48. Quijia, C. R.; Lima, C.; Silva, C.; Alves, R. C.; Frem, R.; Chorilli, M., Application of MIL-100(Fe) in drug delivery and biomedicine. Journal of Drug Delivery Science and Technology 2021, 61, 102217.

49. $\quad$ Feng, D.; Wang, K.; Wei, Z.; Chen, Y.-P.; Simon, C. M.; Arvapally, R. K.; Martin, R. L.; Bosch, M.; Liu, T.-F.; Fordham, S.; Yuan, D.; Omary, M. A.; Haranczyk, M.; Smit, B.; Zhou, H.-C., Kinetically tuned dimensional augmentation as a versatile synthetic route towards robust metal-organic frameworks. Nature Communications 2014, 5 (1), 5723.

50. $\quad$ Wang, K.; Feng, D.; Liu, T.-F.; Su, J.; Yuan, S.; Chen, Y.-P.; Bosch, M.; Zou, X.; Zhou, H.-C., A Series of Highly Stable Mesoporous Metalloporphyrin Fe-MOFs. Journal of the American Chemical Society 2014, 136 (40), 13983-13986.

51. Ahamad, M. N.; Khan, M. S.; Shahid, M.; Ahmad, M., Metal organic frameworks decorated with free carboxylic acid groups: topology, metal capture and dye adsorption properties. Dalton Transactions 2020, 49 (41), 14690-14705.

52. $\mathrm{Au}, \mathrm{V}$. K.-M., Recent Advances in the Use of Metal-Organic Frameworks for Dye Adsorption. Frontiers in Chemistry 2020, 8 (708).

53. Ai, L.; Zhang, C.; Meng, L., Adsorption of Methyl Orange from Aqueous Solution on Hydrothermal Synthesized Mg-Al Layered Double Hydroxide. Journal of Chemical \& Engineering Data 2011, 56 (11), 4217-4225.

54. Song, X.; Kim, T. K.; Kim, H.; Kim, D.; Jeong, S.; Moon, H. R.; Lah, M. S., PostSynthetic Modifications of Framework Metal Ions in Isostructural Metal-Organic Frameworks: Core-Shell Heterostructures via Selective Transmetalations. Chem. Mater. 2012, 24 (15), 30653073. 
55. Kalaj, M.; Cohen, S. M., Postsynthetic Modification: An Enabling Technology for the Advancement of Metal-Organic Frameworks. ACS Central Science 2020, 6 (7), 1046-1057.

56. Seth, S.; Savitha, G.; Moorthy, J. N., Diverse isostructural MOFs by postsynthetic metal node metathesis: anionic-to-cationic framework conversion, luminescence and separation of dyes. Journal of Materials Chemistry A 2015, 3 (45), 22915-22922.

57. Abednatanzi, S.; Gohari Derakhshandeh, P.; Depauw, H.; Coudert, F.-X.; Vrielinck, H.; Van Der Voort, P.; Leus, K., Mixed-metal metal-organic frameworks. Chem. Soc. Rev. 2019, 48 (9), 2535-2565.

58. Das, S.; Kim, H.; Kim, K., Metathesis in Single Crystal: Complete and Reversible Exchange of Metal Ions Constituting the Frameworks of Metal-Organic Frameworks. Journal of the American Chemical Society 2009, 131 (11), 3814-3815.

59. Brozek, C. K.; Dincă, M., Ti3+-, V2+/3+-, Cr2+/3+-, Mn2+-, and Fe2+-Substituted MOF-5 and Redox Reactivity in Cr- and Fe-MOF-5. Journal of the American Chemical Society 2013, 135 (34), 12886-12891.

60. Padial, N. M.; Lerma-Berlanga, B.; Almora-Barrios, N.; Castells-Gil, J.; da Silva, I.; de la Mata, M. a.; Molina, S. I.; Hernández-Saz, J.; Platero-Prats, A. E.; Tatay, S.; Martí-Gastaldo, C., Heterometallic Titanium-Organic Frameworks by Metal-Induced Dynamic Topological Transformations. Journal of the American Chemical Society 2020, 142 (14), 6638-6648. 61. Yang, J.; Wang, X.; Dai, F.; Zhang, L.; Wang, R.; Sun, D., Improving the Porosity and Catalytic Capacity of a Zinc Paddlewheel Metal-Organic Framework (MOF) through Metal-Ion Metathesis in a Single-Crystal-to-Single-Crystal Fashion. Inorg. Chem. 2014, 53 (19), 1064910653.

62. Denny, M. S.; Parent, L. R.; Patterson, J. P.; Meena, S. K.; Pham, H.; Abellan, P.; Ramasse, Q. M.; Paesani, F.; Gianneschi, N. C.; Cohen, S. M., Transmission Electron Microscopy Reveals Deposition of Metal Oxide Coatings onto Metal-Organic Frameworks. Journal of the American Chemical Society 2018, 140 (4), 1348-1357.

63. Masoomi, M. Y.; Morsali, A.; Dhakshinamoorthy, A.; Garcia, H., Mixed-Metal MOFs: Unique Opportunities in Metal-Organic Framework (MOF) Functionality and Design. Angew. Chem. Int. Ed. 2019, 58 (43), 15188-15205.

64. $\quad$ Liu, T.-F.; Zou, L.; Feng, D.; Chen, Y.-P.; Fordham, S.; Wang, X.; Liu, Y.; Zhou, H.-C., Stepwise Synthesis of Robust Metal-Organic Frameworks via Postsynthetic Metathesis and Oxidation of Metal Nodes in a Single-Crystal to Single-Crystal Transformation. Journal of the American Chemical Society 2014, 136 (22), 7813-7816. 